University at Albany, State University of New York

Scholars Archive

Educational \& Counseling Psychology Faculty

Scholarship

Educational \& Counseling Psychology

2020

\title{
Doctor recommendations are related to patient interest and use of behavioral treatment for chronic pain and addiction
}

\author{
Lisa M. McAndrew \\ University at Albany, State University of New York, Imcandrew@albany.edu \\ Alexandria Brunkow \\ University at Albany, State University of New York \\ Margeaux Cannon \\ University at Albany, State University of New York \\ Fiona S. Graff \\ Jessica L. Martin
}

See next page for additional authors

Follow this and additional works at: https://scholarsarchive.library.albany.edu/edpsych_fac_scholar

Part of the Clinical Psychology Commons, Cognitive Behavioral Therapy Commons, Counseling

Psychology Commons, Health Psychology Commons, and the Pain Management Commons

\section{Recommended Citation}

McAndrew, Lisa M.; Brunkow, Alexandria; Cannon, Margeaux; Graff, Fiona S.; Martin, Jessica L.; and Hausmann, Leslie R.M., "Doctor recommendations are related to patient interest and use of behavioral treatment for chronic pain and addiction" (2020). Educational \& Counseling Psychology Faculty Scholarship. 19.

https://scholarsarchive.library.albany.edu/edpsych_fac_scholar/19

This Article is brought to you for free and open access by the Educational \& Counseling Psychology at Scholars Archive. It has been accepted for inclusion in Educational \& Counseling Psychology Faculty Scholarship by an authorized administrator of Scholars Archive. For more information, please contact scholarsarchive@albany.edu. 


\section{Authors}

Lisa M. McAndrew, Alexandria Brunkow, Margeaux Cannon, Fiona S. Graff, Jessica L. Martin, and Leslie R.M. Hausmann 
Brunkow, A., Cannon, M., Graff, F.S., Martin, J.L., Hausmann, L.R.M., \& McAndrew, L.M.*

(2020). Doctor recommendations are related to patient interest and use of behavioral treatment for chronic pain and addiction. Journal of Pain.

https://doi.org/10.1016/j.jpain.2019.12.008

This is the author version of a paper published in Journal of Pain.

\title{
Doctor recommendations are related to patient interest and use of behavioral treatment for chronic pain and addiction
}

\author{
Alexandria Brunkow ${ }^{a *}$, Margeaux Cannon ${ }^{a *}$, Fiona S. Graff ${ }^{b}$, Jessica L. Martin $^{\mathrm{a}}$, \\ Leslie R. M. Hausmann ${ }^{c, d}$, Lisa M McAndrew ${ }^{\mathrm{a}, \mathrm{b}}$
}

${ }^{a}$ University at Albany, State University of New York 1400 Washington Ave. Albany, NY, USA 12222

${ }^{b}$ Veterans Affairs New Jersey Healthcare System 385 Tremont Ave. East Orange, NJ, USA 07018

${ }^{c}$ University of Pittsburgh School of Medicine 3550 Terrace St. Pittsburgh, PA, USA 15213

${ }^{\mathrm{d}}$ Veterans Affairs Pittsburgh Healthcare System University Dr. (151C), Pittsburgh, PA, USA 15240

*These authors contributed equally to the manuscript as first author.

\section{Corresponding author:}

Lisa M. McAndrew

Department of Educational and Counseling Psychology

University at Albany

1400 Washington Ave Ext.

Albany, NY 12222

lisa.mcandrew@va.gov

862-400-3317

Funding/Support: This project was supported by the University at Albany, State University of New York, the Veterans Affairs Health Services Research and Development, Grant Number: 1IK2HX001369, and the Veterans Affairs New Jersey Health Care System, War Related and Illness Study Center. 
Disclosures: There are no conflicts of interest. The views expressed in this article are those of the authors and do not necessarily reflect the position or policy of the Department of Veterans Affairs or the United States government. 


\begin{abstract}
The opioid crisis has highlighted the importance of improving patients' access to behavioral treatments for chronic pain and addiction. What is not known is if patients are interested in receiving these treatments. In this cross-sectional study, over 1000 participants with chronic pain were surveyed using an anonymous online questionnaire on Amazon Mechanical Turk (Mturk) to investigate participants' use of and interest in pharmacological and behavioral treatments for chronic pain and addiction. Participants also indicated whether their doctor had recommended these treatments. The majority of participants reported using medication for their pain $(83.19 \%)$ and that their doctor recommended medication (85.05\%), whereas fewer participants reported using $(67.45 \%)$ and being recommended to $(62.82 \%)$ behavioral treatments. We found $63.67 \%$ of participants screened positive for possible opioid misuse; those who screened positive were more interested in receiving behavioral treatments than those who did not screen positive. Participants who received treatment recommendations were more likely to be interested in receiving those treatments as compared to participants who did not. The results suggest that recommendations for behavioral treatments and interest in those treatments are related. Results also suggest that patients endorsing behaviors consistent with opioid misuse are interested in behavioral treatments.
\end{abstract}

Perspective: This study provides information around chronic pain patients' treatment interests, treatment receipt, and recommendation receipt for behavioral pain management and addiction treatment. This study could help facilitate communication between patients and doctors regarding available treatments for chronic pain and pain treatment-related addiction problems.

Key words: Chronic pain, behavioral treatment, opioid misuse, addiction, treatment preferences 


\section{Introduction}

Chronic pain is one of the most debilitating, difficult to treat, chronic health conditions and affects at least $20 \%$ of the American adult population. ${ }^{7}$ In addition to the direct impact on quality of life via health consequences, chronic pain is widely believed to be causally related to the current opioid epidemic. ${ }^{24}$

Opioid pain medications are one of the most frequently used treatments for chronic pain, ${ }^{16}$ despite limited evidence of their long-term efficacy. ${ }^{10,21}$ Risks of opioid pain medication include abuse, addiction, and overdose. ${ }^{10}$ As many as $62 \%$ of patients with chronic pain who are prescribed opioids misuse them. ${ }^{39}$

Despite opioids being a commonly used treatment for chronic pain, clinical practice guidelines strongly emphasize behavioral approaches as first-line treatments for chronic pain. ${ }^{9,10,34}$ There is ample evidence to support the efficacy of behavioral approaches to treat pain, including cognitive behavioral therapy (CBT),${ }^{18,30}$ health coaching, ${ }^{38}$ behavioral activation ${ }^{28}$ and mindfulness. $^{18}$

There are likely numerous reasons for the common use of opioid pain medication over behavioral approaches, including pressure on physicians to provide rapid pain relief, ${ }^{27}$ economic and time demands during medical appointments, ${ }^{23}$ and barriers to accessing behavioral treatments, such as high cost, variable accessibility, and low motivation. ${ }^{2}$ For instance, patients may not be able to locate a behavioral health provider with expertise in chronic pain, insurance may not be accepted, and behavioral treatments often require practice between sessions for maximal benefit. In addition, physicians report concerns about negative interactions with patients if they recommend behavioral treatments. ${ }^{17}$ 
Both patients and providers may perceive discussions around chronic pain treatment as uncomfortable, with providers feeling pressure to prescribe opioid medication, and patients reporting concerns that their doctors view them as drug-seeking. ${ }^{26}$ This mutual discomfort and lack of a shared understanding of patients' pain treatment preferences indicates that there is a need for more information regarding patients' preferences. For instance, it is unknown whether there is an association between doctors' recommendations and patients' interest in behavioral treatments. This additional understanding could inform a more candid and effective conversation about pain treatment. Further, it is not known whether patients misusing opioids are less interested in behavioral approaches, as is commonly perceived by physicians. ${ }^{3}$ Information about patient interests and preferences is needed to guide public health approaches to increase use of behavioral treatments for chronic pain.

The aims of the current study are to better understand patients' receipt of recommendations for chronic pain treatments from their doctor, as well as their interest in and use of treatments for chronic pain. We were interested in understanding whether there is a relationship between doctor recommendation for a treatment and patients' interest in this treatment. We also aimed to determine whether patients misusing opioids are less likely to be interested in behavioral treatments. We hypothesized that (a) more patients will have received and have been recommended to receive medication treatment than behavioral treatment; (b) there will be a positive association between providers recommending behavioral treatments and patients' interest in behavioral treatments; and (c) patients who report misusing opioids will be less interested in behavioral treatments than medication. 


\section{Methods}

\section{Participants}

Since we were interested in understanding the treatment interest of a large community sample of chronic pain patients, including those who may be misusing opioids, participants were recruited through Amazon's Mechanical Turk (Mturk). Mturk provides a user-friendly interface for participants and allows researchers to collect data from a diverse participant pool. ${ }^{4}$ Previous research has found participants on Mturk are willing to admit to higher rates of addiction, ${ }^{36}$ perhaps due to the anonymous nature of the format. Mturk has been found to be reliable and valid for populations with health concerns,${ }^{35}$ including addiction. ${ }^{20}$ All Mturk workers were able to access the survey, but screening questions were included at the beginning of the survey to ensure respondents met the inclusion criteria. Those that did not endorse the inclusion criteria were directed to a thank you page and exited out of the survey.

A total of 1399 participants accessed the study over a period of approximately one week during August of 2018. Participants were allowed to proceed with the survey if they answered "Yes" to all of the following inclusion criteria questions: "Are you over the age of 18?"; "Do you have chronic pain?"; "Do you receive your healthcare in the United States?" Based on these criteria, 349 participants were excluded, leaving a final study sample of 1050 participants (550 women, 485 men, and 4 other; 12 participants did not identify a gender). More detailed demographic information about participants is reported in Table 1. 


\begin{tabular}{|c|c|c|}
\hline Demographic & Category & Mean $(\mathbf{S D}) / \%(\mathbf{N})$ \\
\hline Age & & $37.50(11.94)$ \\
\hline \multirow[t]{3}{*}{ Gender } & Female & $52.38 \%(550)$ \\
\hline & Male & $46.19 \%(485)$ \\
\hline & Other & $0.38 \%(4)$ \\
\hline \multirow[t]{3}{*}{ Work Status } & Working (Full or Part time) & $73.42 \%(771)$ \\
\hline & Student (Full or Part time) & $6.38 \%(67)$ \\
\hline & Not working & $27.05 \%(284)$ \\
\hline Disability benefits & Disability benefits ( $\%$ yes) & $20.38 \%(214)$ \\
\hline \multirow[t]{2}{*}{ Level of education } & $\begin{array}{l}\text { High school/GED/Trade school/Some } \\
\text { college }\end{array}$ & $41.90 \%(440)$ \\
\hline & College graduate or higher & $57.90 \%(608)$ \\
\hline \multirow[t]{2}{*}{ Marital status } & Married/living as married & $51.71 \%(543)$ \\
\hline & Not married & $47.71 \%(501)$ \\
\hline \multirow[t]{2}{*}{ Ethnicity } & Hispanic/Latino & $11.90 \%(125)$ \\
\hline & Not Hispanic/Latino & $87.33 \%(917)$ \\
\hline \multirow[t]{7}{*}{ Race } & American Indian & $1.24 \%(13)$ \\
\hline & Asian & $5.05 \%(53)$ \\
\hline & Native Hawaiian/Pacific Islander & $0.19 \%(2)$ \\
\hline & Black/African American & $9.05 \%(95)$ \\
\hline & White & $80.48 \%(845)$ \\
\hline & More than one race & $1.90 \%(20)$ \\
\hline & Other & $1.52 \%(16)$ \\
\hline \multirow[t]{2}{*}{ Military Service } & No & $87.62 \%(920)$ \\
\hline & Yes & $12.29 \%(129)$ \\
\hline \multirow[t]{2}{*}{ Community } & Urban & $65.05 \%(683)$ \\
\hline & Rural & $34.38 \%(361)$ \\
\hline
\end{tabular}


Table 1. Descriptive data for sample.

Note: Totals vary, as not all participants completed every question and some questions allowed for multiple responses.

\section{Measures}

Behavioral treatment measures. Survey items were developed by the research team based on clinical consensus of treatments typically indicated for chronic pain and available in the Veterans Affairs healthcare system. The survey included brief descriptions of behavioral and pharmacological treatments for chronic pain and addiction including cognitive behavioral therapy (CBT), health coaching, behavioral activation, mindfulness, positive practice, medication, and addiction treatment (see Appendix A). Participants were asked to indicate if they had received each of these treatments in the past $(\mathrm{Y} / \mathrm{N})$, whether their doctor had recommended each treatment $(\mathrm{Y} / \mathrm{N})$, and whether they were interested in receiving each treatment (Yes very interested; Somewhat interested; Not very interested; Not interested at all).

Multidimensional Pain Inventory. The West Haven-Yale Multidimensional Pain Inventory ${ }^{19}$ is a well-validated self-report measure of important dimensions of the experience of people with chronic pain. While all the participants in the sample endorsed chronic pain, respondents were asked to rate pain level at the present moment, severity during the past week, and suffering due to pain on a scale of $0-6$, with $0=$ not severe at all and $6=$ extremely severe.

Pain Disability Index. The Pain Disability Index ${ }^{33}$ is a self-report instrument used to assess the degree to which chronic pain interferes with various daily activities. Participants were asked to answer how much their pain negatively impacts their life in the following areas: family/home responsibilities, recreation, social activity, occupation, sexual behavior, self-care, 
and life-support activities. Respondents answered on a scale of $0-10$, with $0=$ no disability and $10=$ worst disability.

Self-report measures of medication use. Respondents were asked whether they are currently taking any medications for their chronic pain $(\mathrm{Y} / \mathrm{N})$ and whether they are taking any opioid medications (Y/N; e.g., Hydrocodone, Oxycodone, Morphine, Fentanyl, Codeine, Methadone, Meperidine, Propoxyphene, and Tramadol). Brand names for each medication were provided as examples (e.g., Lorcet, Vicodin, Percocet, Dilaudid, Opana, Demerol, etc.).

Current Opioid Misuse Measure (COMM). Current Opioid Misuse Measure $(\mathrm{COMM})^{5}$ is a 17 -item well-validated self-report questionnaire of various behaviors, emotional, and psychiatric problems related to opioid misuse (e.g., In the past 30 days, how often have you taken your medications differently from how they are prescribed?). Items are rated from 0 (never) to 4 (often) with a total maximum score of 68. A score of "9" or higher is considered positive for risk of opioid misuse. The full 17-item COMM includes a question around thoughts of self-harm, which was removed because this research was conducted anonymously and we had no ability to follow up on suicidal ideation, ${ }^{8}$ resulting in a maximum possible score of 64 . As a result, a cutoff score of " 8 " to indicate risk of opioid misuse was used for data analysis in the present study. The Cronbach's alpha among our sample was .771, which is considered acceptable. ${ }^{15}$ For comparison, Martel and colleagues assessed for opioid misuse among patients with chronic pain and found an alpha coefficient of .74 after removing items related to experience of psychiatric issues. ${ }^{25}$

Patient Health Questionnaire-2 (PHQ-2). The PHQ-222 is a two-item screen for depression. It inquires, “Over the last 2 weeks, how often have you been bothered by the following problems? 1. Little interest or pleasure in doing things. 2. Feeling down, depressed or 
hopeless." Items are rated from 0 (Not at all) to 3 (Nearly every day) with a total maximum score of 6. A positive depression screen is indicated by a score of " 3 " or higher.

Demographic questions. Respondents were asked to report their age, gender, ethnicity, race, education level, marital status, employment status, military service, disability benefit status and whether they lived in a rural or urban area (see Table 1).

\section{Procedures}

This study was a cross-sectional, between-subjects design. All participants electronically reviewed and affirmed their understanding of an informed consent form prior to study participation, and all procedures were approved by the SUNY Albany Institutional Review Board. The survey took about 15 minutes to complete. The questionnaire responses were housed on PsychData to ensure no identifying information, such as IP addresses, was associated with participants' responses. ${ }^{29}$ At the end of the survey, participants were given a completion code to enter into Mturk for payment. Eligible participants who completed the survey were compensated $\$ 1.00$ for their time.

\section{Data analysis}

All data were analyzed using SPSS v.25. Data were checked for low response rate $(<20 \%$ of items completed for any one measure) and no cases were excluded. Descriptive data for categorical variables were presented as percentage responding "yes," and were analyzed using chi-square tests. We examined bivariate correlations between demographic and clinical variables, interest in treatments, recommendations for treatments, and receipt of treatments.

For chi-square analyses including respondents' interest in treatments, responses of "Yes very interested" and "Somewhat interested" were grouped and re-coded as "Interested." 
Responses of "Not very interested" and "Not interested at all" were grouped and re-coded as "Not interested."

\section{Results}

\section{Descriptive Statistics}

Participants were between 19 and 81 years old $(M=37.50, S D=11.94)$. About half of the sample were female $(52.38 \%)$. A high percentage of our sample were white $(80.48 \%)$, had a college degree or higher (57.9\%), and working (73.42\%; Table 1).

The participants' responses on the PHQ-2 indicated that $46 \%$ of our sample scored above the cutoff for positive depression screen, indicated by a score of " 3 " or above. The mean score on the PHQ-2 was $2.55(S D=1.70)$, out of a maximum of 6 .

The average level of pain in the present moment was $3.21(S D=1.25)$ out of 6 and 3.76 $(S D=1.20)$ out of 6 in the past week. The average suffering experienced due to pain was 3.75 $(S D=1.22)$ out of 6 . The pain impairment index showed an average pain disability of $4.61(S D=$ 2.25) out of 10 .

There was a high rate of endorsement of behaviors associated with opioid misuse: $63.67 \%$ of those receiving opioid treatment screened positive for being at risk of opioid misuse, indicated by a score of " 8 " or above. The mean score on the COMM was $28.17(S D=13.43)$, out of a maximum of 64 .

\section{Receipt of Treatments}

Overall, $32.55 \%$ of participants reported having received none of the behavioral treatments indicated on the survey. Of the participants who had received any behavioral treatment $(67.45 \%)$, on average they received $2.32(S D=1.26)$ behavioral treatments. Most participants received medication for their chronic pain (83.19\%). Table 2 shows the percent of 
participants who received each of the treatments. The least received treatments were addiction treatment (15.27\%) and behavioral activation $(23.00 \%)$ and the most received treatments were medication $(83.19 \%)$ and health coaching $(37.04 \%)$.

\begin{tabular}{|c|c|c|c|c|c|c|}
\hline \multirow[t]{2}{*}{ Treatment } & \multirow{2}{*}{$\begin{array}{l}\text { Received } \\
\text { Treatment } \\
(\%)\end{array}$} & \multirow{2}{*}{$\begin{array}{l}\text { Provider } \\
\text { Recommended } \\
\text { Treatment } \\
(\%)\end{array}$} & \multicolumn{4}{|c|}{ Interest in receiving treatment } \\
\hline & & & $\begin{array}{l}\% \text { Very } \\
\text { interested }\end{array}$ & $\begin{array}{l}\% \\
\text { Somewhat } \\
\text { Interested }\end{array}$ & $\begin{array}{l}\% \text { Not } \\
\text { very } \\
\text { interested }\end{array}$ & $\begin{array}{l}\% \text { Not at } \\
\text { all } \\
\text { interested }\end{array}$ \\
\hline CBT & $36.49 \%$ & $33.91 \%$ & $22.67 \%$ & $42.44 \%$ & $18.31 \%$ & $16.57 \%$ \\
\hline $\begin{array}{l}\text { Health } \\
\text { Coaching }\end{array}$ & $37.04 \%$ & $41.08 \%$ & $29.22 \%$ & $36.16 \%$ & $18.80 \%$ & $15.81 \%$ \\
\hline $\begin{array}{l}\text { Behavioral } \\
\text { Activation }\end{array}$ & $23.00 \%$ & $22.93 \%$ & $24.10 \%$ & $35.37 \%$ & $21.19 \%$ & $19.34 \%$ \\
\hline Mindfulness & $32.98 \%$ & $27.13 \%$ & $27.71 \%$ & $35.56 \%$ & $18.90 \%$ & $17.83 \%$ \\
\hline $\begin{array}{l}\text { Positive } \\
\text { Practice }\end{array}$ & $28.45 \%$ & $28.03 \%$ & $26.59 \%$ & $35.93 \%$ & $19.75 \%$ & $17.73 \%$ \\
\hline $\begin{array}{l}\text { Addiction } \\
\text { Treatment }\end{array}$ & $15.27 \%$ & $16.02 \%$ & $8.11 \%$ & $12.93 \%$ & $17.28 \%$ & $61.68 \%$ \\
\hline Medication & $83.19 \%$ & $85.05 \%$ & $40.00 \%$ & $33.69 \%$ & $15.63 \%$ & $10.68 \%$ \\
\hline
\end{tabular}

Table 2. Receipt, recommendation for, and interest in treatments.

\section{Recommendations for Treatments}

Overall, $37.18 \%$ of participants reported receiving no recommendations for behavioral treatments. Of the participants who received any behavioral treatment recommendations $(62.82 \%)$, on average they received recommendations for $2.11(S D=1.50)$ behavioral treatments. Most participants reported receiving recommendations for medication $(85.05 \%)$. 
Table 2 shows the percent of participants who received recommendations for each of the treatments. The least recommended treatments were addiction treatment (16.02\%) and behavioral activation $(22.93 \%)$ and the most recommended treatments were medication $(85.05 \%)$ and health coaching $(41.08 \%)$.

\section{Interest in Treatments}

Overall, $89.05 \%$ of participants reported being very or somewhat interested in receiving at least one behavioral treatment and $73.69 \%$ of participants reported being very or somewhat interested in medication. Participants reported being interested in an average of $3.15(S D=1.70)$ behavioral treatments. Table 2 shows the percent of participants interested in each of the treatments. The behavioral treatments that participants reported the most interest in were health coaching $(65.38 \%)$, mindfulness $(63.27 \%)$, and positive practice $(62.52 \%)$.

\section{Bivariate Correlations Between Variables}

Bivariate correlations show significant positive associations between positive depression screen, pain severity, pain disability, and behavioral treatment interest, recommendation, and receipt. There was not a consistent relationship between age, education or gender and interest, recommendation, or receipt of treatments. Table 3 shows the bivariate correlations between age, gender, education, depression, disability, pain severity, pain disability, and interest in treatment, treatment recommendations, and treatment receipt. 


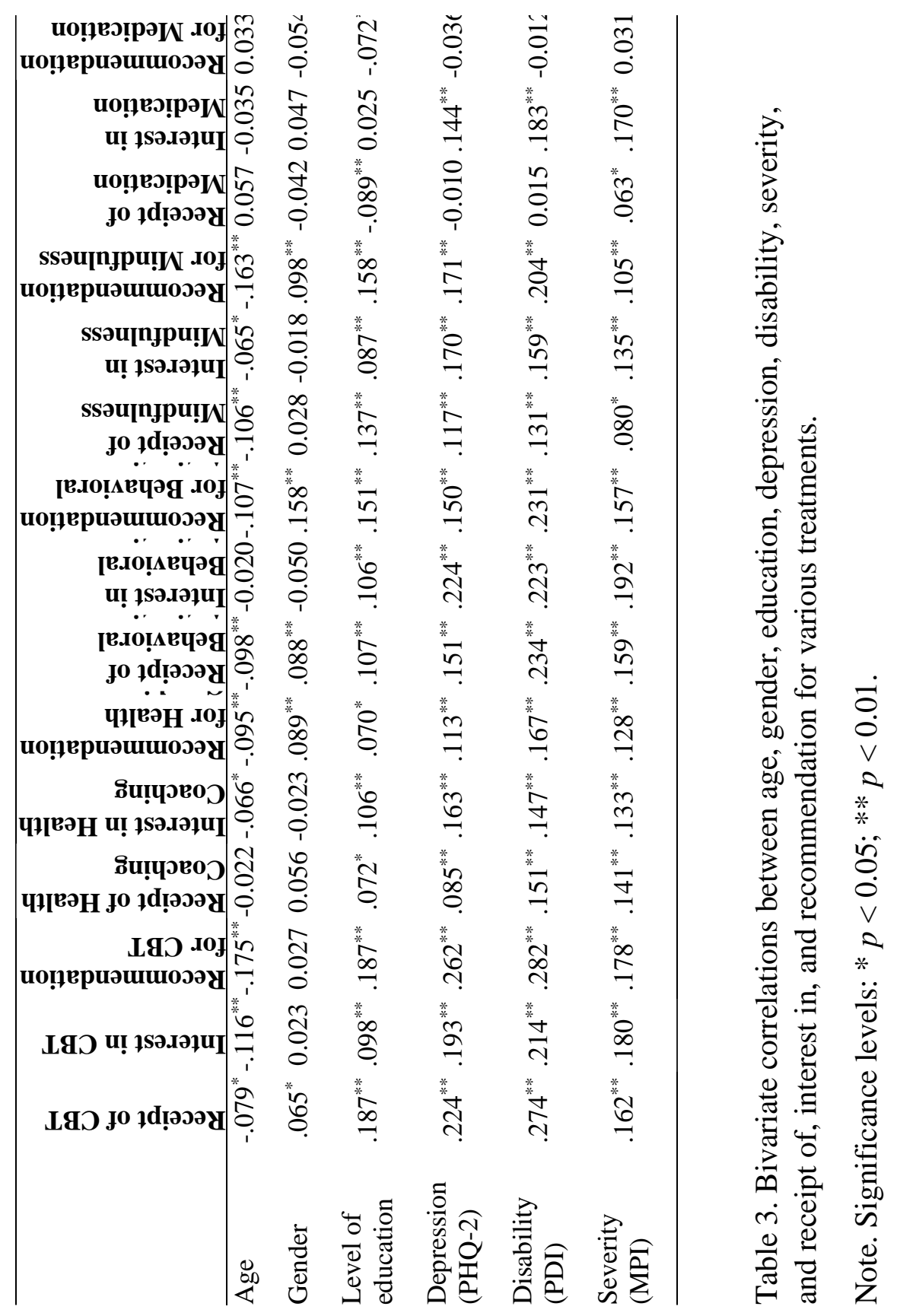

Interest in Treatment for Patients Recommended to Treatment vs. Not Recommended to Treatment

Chi-square analysis showed that participants who reported having received a recommendation for a treatment were more interested in receiving that treatment as compared to 
those who did not receive a recommendation for that treatment. The chi-square was significant for all treatments, including both behavioral and pharmacological treatments (Figure 1).

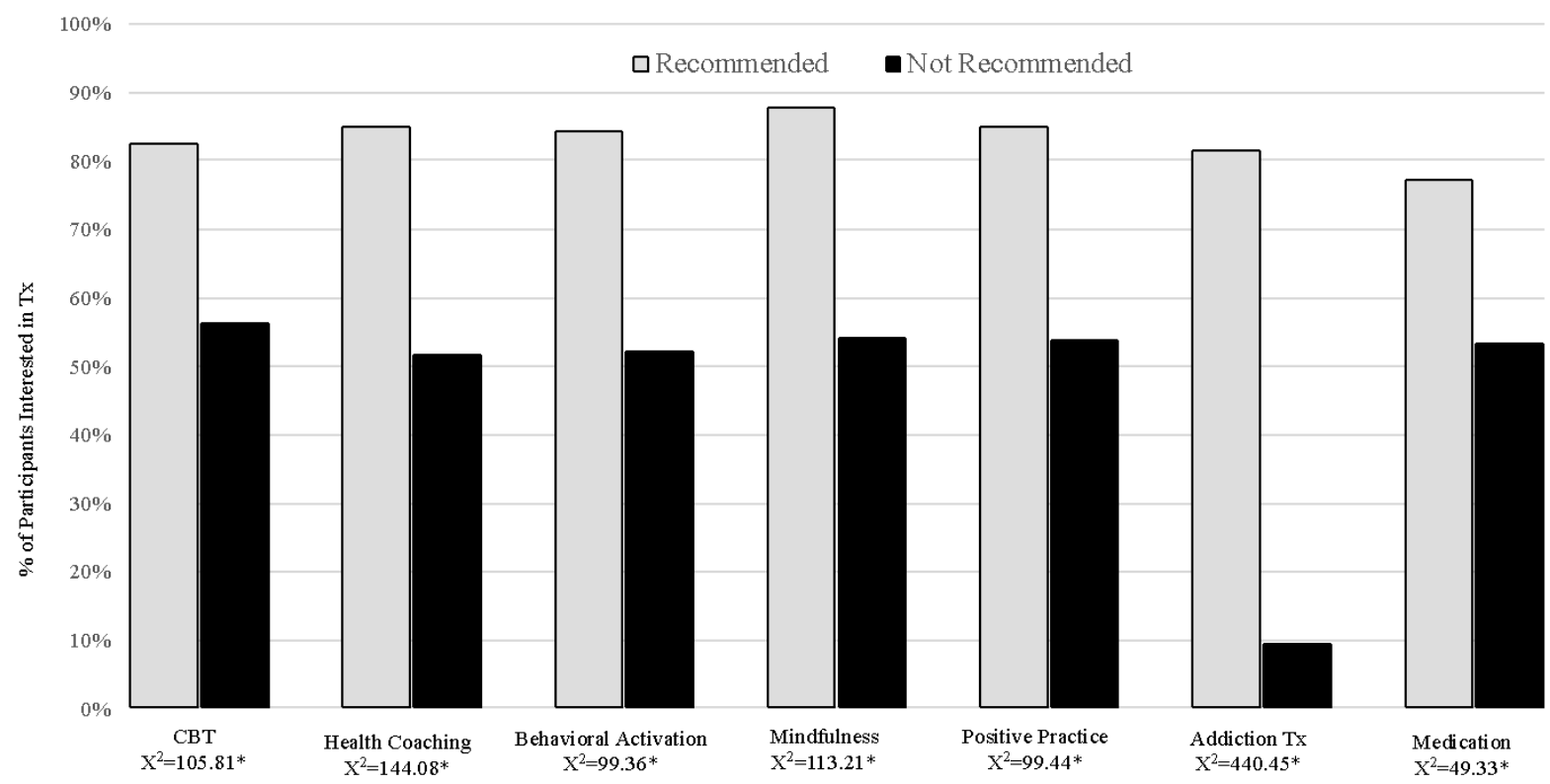

Figure 1. Percent of participants interested in treatments by provider recommendation/no provider recommendation. $*$ indicates $p=.0001$.

\section{Interest in Treatment for Patients Misusing Opioids vs. Not Misusing Opioids}

Chi-square analysis showed that participants receiving opioids who screened positive for opioid misuse were significantly more interested in behavioral treatments, including addiction treatment, as compared to those not misusing opioids. There was no difference in interest in medication treatment for patients who screened positive for opioid misuse as compared to those who did not screen positive for opioid misuse (Figure 2). 


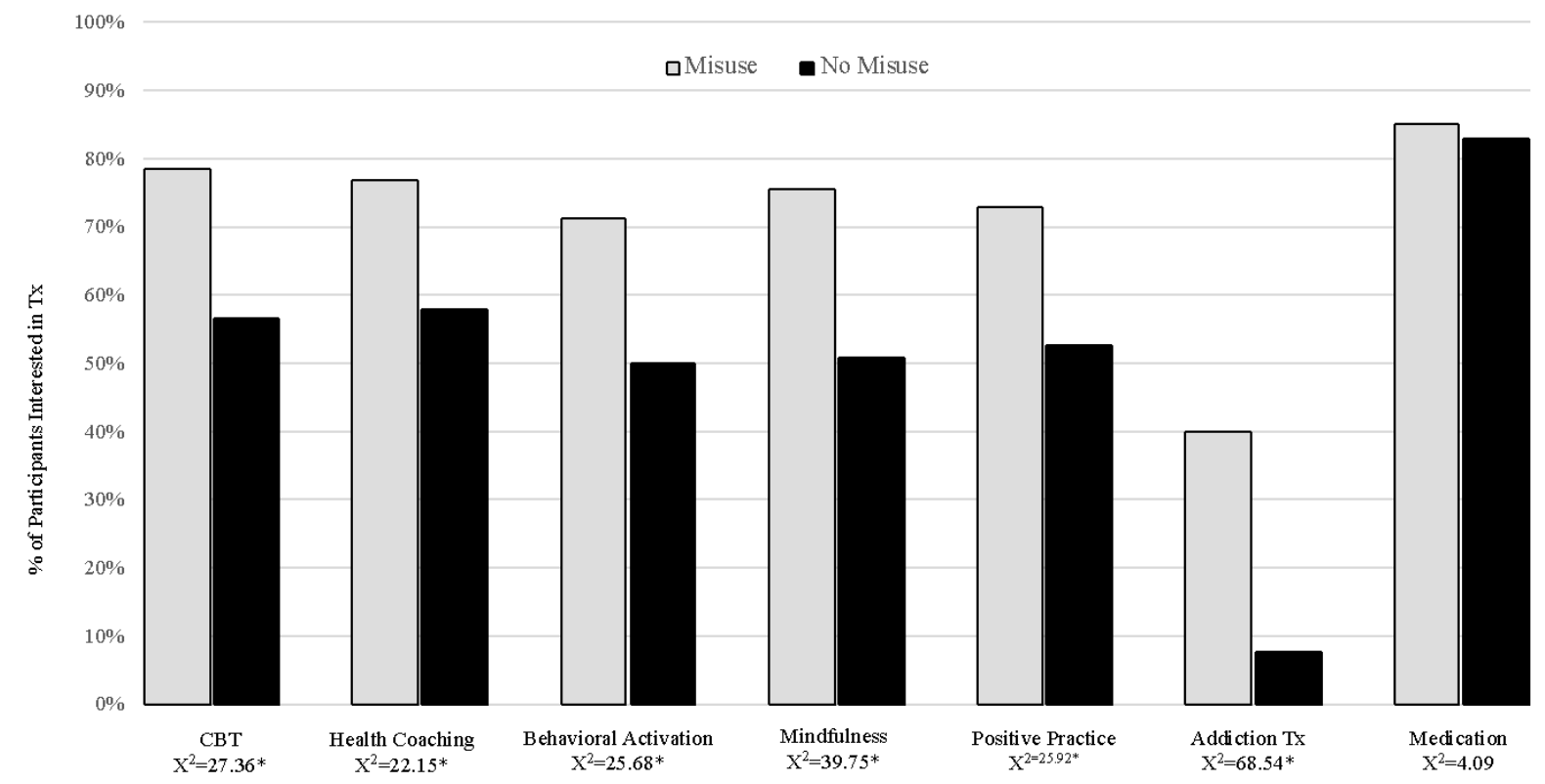

Figure 2. Percent of participants interested in treatments by risk of opioid misuse/no risk of opioid misuse. $*$ indicates $p=.0001$.

\section{Discussion}

This study aimed to understand recommendations by doctors, as well as patients' interest in, and actual treatment receipt across a range of approaches for chronic pain among a large sample of community respondents with chronic pain. Additional aims were to understand whether treatment interest varied by doctor recommendation or risk of opioid misuse.

We found that patients with chronic pain were overwhelmingly interested in receiving behavioral treatments, with higher rates of interest in receiving these treatments than actual receipt of these treatments or receipt of recommendations for these treatments. Of the behavioral treatments, individuals were most interested in health coaching, mindfulness and positive practice.

Importantly, we found that provider recommendations were associated with treatment interest: respondents whose doctors recommended treatments were also more likely to be 
interested in receiving these treatments as compared to those who did not receive a recommendation. This was true for all treatments, including addiction treatment. Behavioral treatments that were recommended with the highest frequency were cognitive-behavioral therapy and health coaching, perhaps reflecting greater awareness and availability of these treatments as compared to the others. While we are unable to determine the direction of the relation between provider recommendation and patient treatment interest due to the cross-sectional nature of this study, findings are supportive of the hypothesis that provider recommendations may be associated with increased patient interest in receiving the intervention.

Importantly, respondents who misused opioids were more interested in receiving behavioral treatments for their pain and also more interested in receiving addiction treatment as compared to those who were not misusing opioids. Patients with chronic pain who misuse opioids are often negatively perceived as resistant to behavioral pain and addiction treatments in the healthcare and broader community. ${ }^{6}$ Our findings indicate, however, that patients who show signs of opioid misuse are interested in behavioral treatment options. This may reflect that opioid medication is not effectively managing pain and thus patients are interested in other forms of therapy to replace or serve as adjuncts to medication therapy. Our findings also suggest that patients who endorse behaviors associated with opioid misuse are likely to be receptive to addiction treatment recommendations.

Our data suggest public health efforts do not need to focus on convincing patients to consider behavioral treatments. Rather, public health efforts are needed to train providers to more frequently and perhaps more effectively make recommendations for behavioral treatments. While, in general, provider recommendations and interest are associated, not all patients who were recommended a treatment were interested. Previous research finds that when not delivered 
correctly, a recommendation for behavioral treatments can feel like the provider is discrediting or misunderstanding the patient's pain, or implying the pain is "all in their head". ${ }^{12,13}$ Public health efforts are likely also needed to increase the availability of these treatments. Our data found that few participants received these behavioral treatments and previous research supports the multiple barriers of treatments receipt for pain. ${ }^{2}$

Moreover, our data suggest that both patients and providers should be apprised of the full menu of treatment options for chronic pain, including integrative pharmaceutical and behavioral approaches. Previous research suggests that patients typically benefit from interdisciplinary approaches to pain management, including lifestyle modification, movement therapies, and mind-body based treatments. ${ }^{31}$ Patients' behavioral treatment preferences did not always exactly mirror doctor recommendations, and those who had received behavioral recommendations typically noted interest in several approaches, suggesting that there may be room for discussion of multiple approaches to pain management. Discussing these multiple approaches may ultimately increase receipt, as patients cite having a wide array of treatment options as a facilitator to using behavioral treatments for chronic pain. ${ }^{2}$ In our sample, depression, pain severity and pain-related disability were related to interest, recommendation, and receipt of behavioral treatments. This means that depression, pain severity, and pain-related disability may be important indicators for behavioral treatment interest and use.

Strengths of this study include data being collected via Mturk, which is an anonymous online method that may have facilitated more honest and genuine responses regarding treatment interest and risk of opioid misuse. ${ }^{36}$ Mturk also has limitations. While a large community sample was used, there may be characteristics unique to this sample which limit generalizability to the broader population. Research has shown that Mturk samples tend to be younger, more educated, 
and have higher rates of depression than nationally representative sources,${ }^{36}$ and this finding may be accurate for our sample as well. For example, our sample may have been younger, with more education, and a greater proportion reporting moderate or worse pain when compared to a nationally-representative survey such as the Medical Expenditure Panel Survey. ${ }^{32}$ Additionally, nearly half of the present study's sample scored at or above the cutoff on a brief depression screen. Although positive screen does not necessarily equate to diagnosis, this is a rate closer to the prevalence of depression found in pain clinics or inpatient pain programs as compared to the general population. ${ }^{1}$ In a study of Veterans' pain treatment preferences, those with higher educational attainment and worse mental health symptoms were more likely to have used psychological/behavioral modalities. ${ }^{11}$ As such, this sample may represent a subgroup of patients with pain and depression symptoms closer to a clinical population, which may, in turn, affect treatment preferences.

Another limitation was that we included select behavioral interventions and thus, did not evaluate interest in other approaches to chronic pain such as physical therapy and diet modifications. Also, this was a cross-sectional study and thus we cannot draw definitive conclusions regarding the influence of treatment interest on subsequent receipt. Future research could examine whether pain severity or disability interact with opioid use/misuse to predict treatment recommendation, interest, and receipt, as these examinations were beyond the scope of this paper. While this study focused on individual interest in treatment, it should be noted that there are multiple factors affecting the use of and access to chronic pain treatment modalities, including changes in approaches to pain and pain treatment (i.e., biopsychosocial framework, biomedical model, etc.),${ }^{14}$ as well as shifts in funding and public health policy. ${ }^{37}$ These should be explored in future studies. 
Overall, this study underscores the importance of developing, discussing and recommending alternative treatment approaches to the management of chronic pain. Our findings suggest a high rate of interest in non-pharmacological, behavioral treatments, which was even more prevalent among patients whose providers recommended these treatments and among patients misusing opioids. Rather than assume patients prefer medication for chronic pain, providers should explore a broad range of behavioral treatment options with patients. 


\section{References}

1. Bair MJ, Robinson RL, Katon W, Kroenke K: Depression and pain comorbidity: A literature review. Archives of Internal Medicine, 163:2433-2445, 2003

2. Becker WS, Dorflinger L, Edmond SN, Islam L, Heapy AA, Fraenkel L: Barriers and facilitators to use of non-pharmacological treatments in chronic pain. BMC Family Practice 18:41, 2017

3. Buchman DZ, Ho A, Illes J: You present like a drug addict: Patient and clinician perspectives on trust and trustworthiness in chronic pain management. Pain Medicine 17:1394-1406, 2016

4. Buhrmester MD, Talaifar S, Gosling SD: An evaluation of Amazon's Mechanical Turk, its rapid rise, and its effective use. Perspectives on Psychological Science 13:149-154, 2018

5. Butler SF, Budman SH, Fernandez KC, Houle B, Benoit C, Katz N, \& Jamison RN: Development and validation of the current opioid misuse measure. Pain 130:144-156, 2007

6. Cooper S, Nielsen S: Stigma and social support in pharmaceutical opioid treatment populations: a scoping review. International Journal of Mental Health \& Addiction $15: 452-469,2017$

7. Dahlhamer J, Lucas J, Zelaya C, Nahin R, Mackey S, DeBar L, Kerns R, Von Korff M, Porter L, \& Helmick C: Prevalence of chronic pain and high-impact chronic pain among adults — United States, 2016. Morbidity and Mortality Weekly Report 67:1001-1006, 2018

8. Deeley ST, Love AW: Does asking adolescents about suicidal ideation induce negative mood state? Violence and Victims 25:677-88, 2010 
9. Department of Veterans Affairs: VA/DoD clinical practice guideline for opioid therapy for chronic pain. Retrieved July 12, 2019 from https://www.healthquality.va.gov/guidelines/pain/cot/

10. Dowell D, Haegerich TM, Chou R: CDC guideline for prescribing opioids for chronic painUnited States, 2016. Journal of the American Medical Association 315: 1624-1645, 2016 11. Edmond SN, Becker WC, Driscoll MA, Decker SE, Higgins DM, Mattocks KM, Kerns R, \& Haskell S. G: Use of non-pharmacological pain treatment modalities among veterans with chronic pain: Results from a cross-sectional survey. Journal of General Internal Medicine 33: 54-60, 2018.

12. Ernst MM, O’Brien HL, Powers SW: Cognitive-behavioral therapy: How medical providers can increase patient and family openness and access to evidence-based multimodal therapy for pediatric migraine. Headache 55:1382-1396, 2015

13. Frantsve LME, Kerns RD: Patient-provider interactions in the management of chronic pain: Current findings within the context of shared medical decision making. Pain Medicine $8: 25-35,2007$

14. Gatchel RJ, Peters ML, Fuchs PN, Turk DC: The biopsychosocial approach to chronic pain: scientific advances and future directions. Psychol. Bull, 133:581-624, 2007

15. George D, Mallery P (eds): SPSS for Windows step by step: A simple guide and reference. 11.0 update, 4th ed. Boston, Allyn \& Bacon, 2003

16. Hengstebeck E, Roskos S, Breejen K, Arnetz B, Arnetz J: Clinical pain research: Chronic pain disrupts ability to work by interfering with social function: A cross-sectional study. Scandinavian Journal of Pain 17:397-402, 2017 
17. Henry SG, Bell RA, Fenton JJ, Kravitz RL: Communication about chronic pain and opioids in primary care: Impact on patient and physician visit experience. Pain 159:371-379, 2018

18. Kerns RD, Sellinger J, Goodin BR: Psychological treatment of chronic pain. Annual Review of Clinical Psychology, 7: 411-434, 2011

19. Kerns RD, Turk DC, Rudy TE: The West Haven-Yale Multidimensional Pain Inventory (WHYMPI). Pain 23:345-356, 1985

20. Kim HS, Hodgins DC: Reliability and validity of data obtained from alcohol, cannabis, and gambling populations on Amazon's Mechanical Turk. Psychology of Addictive Behaviors $31: 85,2017$

21. Krebs EE, Gravely A, Nugent S, Jensen AC, DeRonne B, Goldsmith ES, Kroenke K, Bair MJ, \& Noorbaloochi, S. Effect of opioid vs nonopioid medications on pain-related function in patients with chronic back pain or hip or knee osteoarthritis pain: The SPACE randomized clinical trial. Journal of the American Medical Association, 319:872-882, 2018

22. Kroenke K, Spitzer RL, Williams JB: The Patient Health Questionnaire-2: Validity of TwoItem Depression Screener. Medical Care 41:1284-1292, 2003

23. Lembke A: Why doctors prescribe opioids to known opioid abusers. New England Journal of Medicine 367:1580-1581, 2012

24. Manchikanti L, Fellows B, Janata JW, Pampati V, Grider JS, Boswell MV: Opioid epidemic in the United States. Pain Physician 15:ES9-38, 2012 
25. Martel MO, Dolman AJ, Edwards RR, Jamison, RN, Wasan AD: The association between negative affect and prescription opioid misuse in patients with chronic pain: The mediating role of opioid craving. The Journal of Pain 15:90-100, 2014

26. Matthias MS, Krebs EE, Collins LA, Bergman AA, Coffing J, Bair MJ: "I'm not abusing or anything": Patient-physician communication about opioid treatment in chronic pain. Patient Education and Counseling 93:197-202, 2013

27. Matthias MS, Parpart AL, Nyland KA, Huffman MA, Stubbs DL, Sargent C, Bair MJ: The patient-provider relationship in chronic pain care: Providers' perspectives. Pain Medicine 11:1688-1697, 2010

28. Mazzucchelli TG, Da Silva M: The potential of behavioural activation for the treatment of chronic pain: An exploratory review. Clinical Psychologist 20:5-16, 2016

29. Mechanical turk (Mturk) for online research. (2018, January). UC Berkeley Committee for the Protection of Human Subjects. Retrieved July 12, 2019 from https://cphs.berkeley.edu/mechanicalturk.pdf

30. Morley S, Williams A, Eccleston C: Examining the evidence about psychological treatments for chronic pain: Time for a paradigm shift?. Pain 154:1929-1931, 2013

31. Penney LS, Haro E: Qualitative evaluation of an interdisciplinary chronic pain intervention: outcomes and barriers and facilitators to ongoing pain management. Journal of Pain Research 12:865-878, 2019

32. Nahin RL, Sayer B, Stussman BJ, Feinberg TM: Eighteen-year trends in the prevalence of, and health care use for, noncancer pain in the United States: Data from the Medical Expenditure Panel Survey. The Journal of Pain 20:796-809, 2019. 
33. Pollard CA: Preliminary validity study of the pain disability index. Perceptual and Motor Skills 59:974, 1984

34. Qaseem A, Wilt TJ, McLean RM, Forciea MA: Noninvasive treatments for acute, subacute, and chronic low back pain: A clinical practice guideline from the American College of Physicians. Annals of Internal Medicine 166:514-530, 2017

35. Shapiro DN, Chandler J, Mueller PA: Using Mechanical Turk to study clinical populations. Clinical Psychological Science 1:213-220, 2013

36. Strickland JC, Stoops WW: The use of crowdsourcing in addiction science research: Amazon Mechanical Turk. Experimental and Clinical Psychopharmacology 27:1-18, 2019

37. Tompkins DA, Hobelmann JG, Compton P: Providing chronic pain management in the "Fifth Vital Sign" era: Historical and treatment perspectives on a modern-day medical dilemma. Drug and Alcohol Dependence 173:S11-S21, 2017

38. Thomas ML, Elliott JE, Rao SM, Fahey KF, Paul SM, Miaskowski C: A randomized, clinical trial of education or motivational-interviewing-based coaching compared to usual care to improve cancer pain management. Oncology Nursing Forum 39:39-49, 2012

39. Turk DC, Swanson KS, Gatchel RJ: Predicting opioid misuse by chronic pain patients: a systematic review and literature synthesis. The Clinical Journal of Pain 24:497-508, 2008 


\section{Table Legend}

Table 1. Descriptive data for sample.

Table 2. Receipt, recommendation for, and interest in treatments.

Table 3. Bivariate correlations between age, gender, education, depression, disability, severity and interest in, receipt of, and recommendation for various treatments.

\section{Figure Legend}

Figure 1. Percent of participants interested in treatments by provider recommendation/no provider recommendation.

Figure 2. Percent of participants interested in treatments by risk of opioid misuse/no risk of opioid misuse. 


\section{Appendix A}

\section{Descriptions of Treatments}

Cognitive Behavioral Therapy: There are many things that impact your chronic pain including your emotions, how you think about your pain, and how you behave in response to your pain. This treatment is a time-limited, weekly treatment that teaches you how to relax your body, manage your emotions, and change your thoughts and behaviors to reduce your pain.

Health Coaching: Did you know that how you take care of your health can also impact your pain? This treatment teaches you about how eating well, exercising, improving your sleep and other health changes can reduce your pain. It also teaches you how to make these changes. Behavioral Activation: Pain makes it hard to do the things we want and need to do. Many people with chronic pain have a hard time maintaining relationships, keeping up with housework, and doing hobbies. This treatment helps people with chronic pain regain control over their life by teaching them strategies to increase the activities they like or need to do, despite having pain.

Mindfulness: Pain makes it hard to enjoy the present moment, and often people find themselves being overwhelmed by thoughts about their pain. This treatment helps people with chronic pain remain focused on the present moment, and become aware of their thoughts and body in a nonjudgmental manner that fosters acceptance.

Medication: Certain medications can relieve the intensity of pain symptoms when taken as prescribed by your doctor.

Addiction Treatment: Treatment can help with addiction to medication, alcohol or other substances. 
Positive Practice: Many treatments for pain focus on alleviating pain symptoms or identifying unhelpful thoughts and behaviors that can make pain worse. In contrast, a positive psychological treatment approach focuses on building core human strengths and values that promote overall well-being, even when you have pain. Examples of positive practices include retraining your brain to notice and appreciate good things in your daily life, expressing gratitude, practicing kindness, and identifying and using your own strengths (e.g., bravery, fairness, curiosity). These practices can be cultivated in the context of counseling or independently, using self-help resources. 